\title{
Desenterrando la represión de género: análisis de la violencia ejercida sobre las mujeres durante la Guerra Civil y la dictadura franquista en el suroeste de España
}

Genero-errepresioa ahanzturatik ateratzen: Gerra Zibilean eta diktadura frankistan Espainiako hego-mendebaldean emakumeen aurka gauzatutako indarkeriaren analisia

Unearthing gendered repression: an analysis of the violence suffered by women during the civil war and Franco's dictatorship in Southwestern Spain

\author{
Laura Muñoz-Encinar \\ Universidad de Extremadura / Universidad de Amsterdam \\ Imunozencinar@unex.es \\ https://orcid.org/0000-0002-6512-3824
}

\begin{abstract}
Resumen
La estrategia represiva franquista puesta en práctica a partir del golpe de estado del 17 de julio de 1936 desarrolló mecanismos complejos de castigo físico y psicológico. Dentro del sistema punitivo franquista existió un procedimiento específico aplicado a las mujeres republicanas. En este artículo se realiza un análisis de la represión sufrida por las mujeres durante la Guerra Civil y la dictadura franquista en España. Para ello, han sido analizadas historias de mujeres que sufrieron torturas físicas y psicológicas, junto a fosas comunes que contenían cuerpos de mujeres represaliadas. Mi investigación está basada en un estudio holístico de fuentes orales y documentales junto al registro material de las fosas comunes, desde una perspectiva histórica, arqueológica y forense. Las conclusiones indican que las diferentes estrategias represivas utilizadas por el fascismo español contra la población femenina estuvieron motivadas por la percepción de las mujeres como ciudadanas de segunda clase y, por lo tanto, inferiores a los hombres. Su castigo siguió criterios de ejemplaridad.
\end{abstract}

\section{Palabras clave}

Fosas comunes; estudios de género; arqueología del pasado contemporáneo; antropología forense; historia oral.

\section{Sumario}

1. INTRODUCCIÓN. 2. ÁREA DE ESTUDIO, MATERIALES Y MÉTODOS. 3. EXHUMAR LA VIOLENCIA, REVELAR LOS ROSTROS. 4. CONCLUSIONES: LA VIOLENCIA DE GÉNERO DURANTE LA GUERRA CIVIL Y LA DICTADURA FRANQUISTA EN ESPAÑA. BIBLIOGRAFÍA. 
Laburpena. 1936ko uztailaren 17ko estatu-kolpearen ondorioz praktikara eramandako errepresio-estrategia frankistak zigor fisiko nahiz psikologikoko mekanismo konplexuak garatu zituen. Izan ere, zigor-sistema frankistan prozedura espezifiko bat izan zen emakume errepublikarrei aplikatzeko. Artikulu honetan, emakumeek Espainiako Gerra Zibilean eta diktadura frankistan pairatutako errepresioaren analisi bat egiten da. Horretarako, tortura fisiko eta psikologikoak sufritu zituzten emakumeen historiak aztertu dira, baita emakume errepresaliatuen gorpuak zituzten hobi komunak ere. Ahozko iturrien eta iturri dokumentalen azterketa holistikoan dago oinarritua ikerketa hau, baita hobi komunen miaketa materialean ere, ikuspuntu historiko, arkeologiko eta forentse batetik. Ondorio gisara, esan daiteke faxismo espainiarrak emakumeen kontra erabilitako errepresio-estrategiek arrazoi nagusi bat izan zutela: emakumeak bigarren mailako herritartzat hartzen zituzten, eta, hortaz, gizonak baino gutxiagotzat. Zigor haiek eredugarri bilakatzea izan zuten irizpide.

Gako hitzak. Hobi komunak; genero-ikerketak; iragan garaikideko arkeologia; antropologia forentsea; ahozko historia.

\begin{abstract}
The Francoist repressive strategy unleashed after the coup d'état of 17 July 1936 developed complex mechanisms of physical and psychological punishment. Within Franco's repressive system there was a specific procedure applied to Republican women. In this article, I provide an analysis of the repression suffered by women during the Spanish Civil War and Franco's dictatorship in southwest Spain. For that purpose, I draw on stories of female victims, who suffered physical and psychological humiliation, and on mass graves with bodies of women. The research is based on a holistic study of material, oral and written sources from a historical, archaeological, and forensic anthropological perspective. It is argued that the different repressive strategies used against the female population by Spanish fascism was motivated by the perception of women as second-class citizens and therefore inferior to men. Their punishment followed criteria of exemplarity.
\end{abstract}

Keywords. Mass graves; gendered studies; archaeology of the contemporary past; forensic anthropology; oral history.

\section{Introducción}

El 17 de julio de 1936 se produjo el alzamiento militar contra el gobierno legítimo de la Segunda República en España. El hecho de que la sublevación no consiguiera imponerse en todo el país derivó en la ocupación militar de las zonas no afines al golpe, iniciándose una guerra que, muy lejos de lo esperado, se prorrogó hasta el 1 de abril de 1939 con la completa derrota de la República ${ }^{1}$. Tras la finalización de la guerra se estableció la dictadura del general Francisco Franco que perduró, más allá de su muerte, hasta la aprobación de la Ley para la Reforma Política en $1977^{2}$.

En el estudio de la represión franquista se han definido dos períodos principales. Desde el 17 de julio de 1936 a febrero de 1937, etapa en la que los sublevados actuaron mediante los bandos de guerra, marco en el que se amparaba la violencia extrajudicial. A partir de febrero de 1937 se establecieron los juicios sumarios

1 Espinosa Maestre, 2002.

2 Molinero, 2006. 
de urgencia que funcionaron hasta $1945^{3}$. No obstante, a pesar de la paulatina instrucción de los consejos de guerra como mecanismo punitivo, paralelamente se continuó utilizando la eliminación del oponente sin más trámite que considerarlo incurso en el bando de guerra. Un procedimiento que permitía acabar con cualquier persona según decidiera la autoridad militar. El uso del bando de guerra como método de eliminación no se circunscribió al período del conflicto armado, sino que fue usado también durante el primer franquismo hasta julio de 1948, en la lucha contra la guerrilla armada antifranquista. Junto a la violencia extrema, la represión franquista estuvo caracterizada por tres aspectos principales: el encubrimiento de los crímenes, la destrucción de las pruebas y la propaganda ${ }^{4}$.

El aparato represivo franquista no solo contemplaba la eliminación física de personas, sino que las estrategias albergaban un complejo mecanismo de castigo psicológico que será aplicado desde el inicio mediante insultos, segregación, persecuciones, vejaciones, encarcelaciones, incautaciones de bienes, procesos de depuración, aplicación de la Ley de Responsabilidades Políticas, etc. ${ }^{5}$. Dentro de las múltiples vertientes del aparato represivo franquista existió un procedimiento específico aplicado sobre las mujeres republicanas ${ }^{6}$. Ya fuera porque habían tenido algún tipo de actividad política durante la República o porque eran esposas, madres, hermanas o familiares de republicanos o personas afines al Frente Popu$\operatorname{lar}^{7}$. Las diferentes estrategias represivas utilizadas contra los grupos femeninos por el fascismo español estuvieron motivadas por la percepción de las mujeres como ciudadanas de segunda clase y, por tanto, inferiores a los hombres. Considerando a las mujeres, según Vallejo Nágera, como seres inferiores y volubles, que hacen uso de las revoluciones sociales para dar rienda suelta a sus latentes apetitos sexuales y su crueldad ${ }^{8}$.

La valoración subordinada del género femenino conllevaba la aplicación de otro tipo de castigos que no siempre implicaban expresamente la muerte9. La represión ejercida sobre el género femenino tiene sus propias características ya fuera física, mediante la ejecución, tortura y violaciones generalizadas ${ }^{10}$, primero durante la guerra y después en las cárceles franquistas ${ }^{11}$. O psicológica, mediante la eliminación de los elementos de feminidad con el rapado del cabello y el paseado público

\footnotetext{
Espinosa Maestre, 2011, 2013.

Espinosa Maestre, 2013.

Espinosa Maestre, 2002; Casanova, 2002.

' Espinosa Maestre, 2002; González-Ruibal, 2014.

7 Nash, 2015; Sánchez Sánchez, 2009; Solé, 2016.

8 Vallejo-Nájera, 1939.

9 Solé, 2016.

${ }^{10}$ Richards, 1999; Preston, 2011.

11 Rodrigo, 2008.
} 
tras ingerir aceite de ricino, lo que les causaba una grave diarrea para purificar sus cuerpos, "para que arrojen el comunismo de su cuerpo» ${ }^{12}$. Las mujeres republicanas fueron caricaturizadas como prostitutas ${ }^{13}$, debido a su intento de lograr la emancipación y la igualdad de derechos que el hombre, en contra de la cultura patriarcal y la moral católica ${ }^{14}$. Una situación a la que lamentablemente numerosas mujeres republicanas se vieron abocadas con posterioridad, obligadas a ejercer la prostitución durante la dura posǵuerra debido a la exclusión social y las deplorables condiciones de vida que sufrieron derivadas de la dictadura franquista ${ }^{15}$.

En este artículo se presenta un análisis de la represión sufrida por las mujeres durante la Guerra Civil y la dictadura franquista en el suroeste de España. Para ello, han sido analizadas historias de mujeres que sufrieron torturas físicas y psicológicas, algunas de las cuales fueron asesinadas o desaparecieron. Junto a ello, en algunos casos, proporciono datos obtenidos de fosas comunes que contenían los cuerpos de mujeres ejecutadas, víctimas de represión franquista. Mi investigación está basada en un estudio holístico de fuentes orales y documentales junto al registro material de las fosas comunes, desde una perspectiva histórica, arqueológica y forense ${ }^{16}$. Esta combinación de disciplinas me ha permitido desarrollar un análisis integral de la violencia política contemporánea, que abre nuevas vías para la producción de conocimiento histórico ${ }^{17}$.

\section{2. Área de estudio, materiales y métodos}

La violencia sufrida por las mujeres durante la Guerra Civil y la dictadura franquista ha sido objeto de estudio de numerosas disciplinas en los últimos años. Entre ellas, la Historia ha jugado un papel esencial en el análisis de la represión específica de género -mujeres que fueron víctimas de represión irregular, juzgadas en consejo de guerra, rapadas, paseadas o vejadas física y psicológicamente ${ }^{18}$. También en los últimos años, la arqueología y antropología forense han comenzado a aportar nuevos datos sobre la violencia sexuada con especificidad de género a partir de las exhumaciones de fosas comunes ${ }^{19}$. Dentro de estas contribuciones,

12 Richards, 1999, pp. 58-59.

13 Gómez Bravo, 2009.

14 Nash, 2015.

15 Casanova, 2002.

${ }^{16}$ Muñoz-Encinar, 2016, 2019a; Crossland, 2000, 2009, 2013.

17 Muñoz-Encinar, 2016, 2019a.

18 Preston, 2011; Espinosa, 2021; Casanova, 2002, 2020; Nash, 2013; Vinyes, 2002; González, 2012; Rodrigo y Alegre, 2019.

19 Muñoz-Encinar, 2016, 2019c; González-Ruibal, 2020; Díaz-Ramoneda et al., 2020. 
el estudio de las fosas comunes que contenían los cuerpos de mujeres ha sido abordado generalmente a partir de casos $\operatorname{concretos}^{20}$, y no de manera ǵlobal. No obstante, la reciente publicación de algunos trabajos ha comenzado a paliar este déficit ${ }^{21}$. Algúnos estudios defienden que el porcentaje de mujeres enterradas en las fosas comunes exhumadas hasta el momento en España es del $7 \%^{22}$, mientras que trabajos posteriores reducen la cifra al $3 \%^{23}$.

Mi investigación se ha llevado a cabo en Extremadura, una región ubicada en el suroeste de España. El planteamiento de este trabajo ha estado centrado en el estudio sistemático y diacrónico de la represión a partir de la exhumación de fosas comunes, con el fin de caracterizar las diferentes estrategias represivas franquistas ejercidas sobre las mujeres a lo largo del tiempo. Estas estrategias -y las pautas de comportamiento represivo que de ellas se derivanpodrían ser extrapolables a otros contextos represivos similares en otras zonas del Estado.

La región extremeña incluye dos provincias, Cáceres y Badajoz. En la provincia de Cáceres, el apoyo al golpe fue casi inmediato, desde el 18 de julio ${ }^{24}$. La provincia de Badajoz, por el contrario, vivió el golpe de manera muy distinta, ya que se mantuvo afín al gobierno republicano. Desde principios de agosto, los militares rebeldes llevaron a cabo la conquista de territorios no sublevados. Con el avance de las tropas sublevadas gran parte de la zona central y occidental de la provincia fueron ocupadas durante el verano, hasta que en otoño de 1936 se establecieron las líneas que delimitaban el frente de Extremadura. Posteriormente el frente se redujo significativamente en una nueva ofensiva en 1938, permaneciendo bajo el control republicano hasta el final de la guerra el 1 abril de 1939.

Según las publicaciones recientes, alrededor de 14800 hombres y mujeres murieron extrajudicialmente en la región de Extremadura ${ }^{25}$. Entre ellos, alrededor de 1600 personas murieron como consecuencia de la represión republicana. La represión franquista causó más de 13200 víctimas, entre las se incluyen más de 9200 personas ejecutadas de forma irregular. Las víctimas de represión irregular fueron detenidas ilegalmente por motivos políticos y eliminadas en base a la aplicación del bando de guerra, viǵente entre julio de 1936 y 1948. Su rastro se pierde en el proceso represivo y los cuerpos de las víctimas fueron enterrados en fosas comunes, arrojados a lechos de los ríos o sepultados en minas.

\footnotetext{
${ }^{20}$ Baquero, 2016, 2018.

${ }^{21}$ Muñoz-Encinar, 2019c; González Ruibal, 2020.

22 González-Ruibal, 2020.

${ }^{23}$ Díaz-Ramoneda et al., 2020.

${ }^{24}$ Chaves Palacios, 1997.

25 Chaves Palacios et al., 2013.
} 
Según recientes investigaciones históricas, el número de mujeres víctimas de represión irregular fue menor que el de hombres ${ }^{26}$, tanto para el conjunto del Estado como en la zona objeto de estudio. En la provincia de Badajoz, el 9\% de las víctimas de represión irregular fueron mujeres ${ }^{27}$. Mientras que, en la provincia de Cáceres, la ejecución de mujeres representa el $7 \%$ de las muertes como consecuencia de la aplicación del bando de guerra ${ }^{28}$. No obstante, es importante tener en cuenta que existe un número indeterminado de mujeres ejecutadas de las que no existe información documental y la única evidencia que tenemos sobre estos casos proviene de fuentes orales. En cuanto al número de mujeres que fueron procesadas mediante consejo de guerra fue también menor que el de hombres: el $10 \%$ del total de las víctimas juzǵadas en la provincia de Cáceres ${ }^{29}$, y el $5 \%$ de las víctimas en Badajoz ${ }^{30}$ fueron mujeres. La mayoría de ellas condenadas a penas de prisión, mientras que las penas de muerte se redujeron significativamente.

Desde que se iniciaran las exhumaciones con carácter científico, entre los años 2003 y 2019, se han abierto un total de 45 fosas comunes en Extremadura, de las que he analizado la evidencia arqueológica y antropológica forense en 35 $\operatorname{casos}^{31}$. El número mínimo de individuos exhumados en estas fosas es de 299, una cifra que representa el 3,2\% del total de víctimas de represión irregular ${ }^{32}$. Dentro de los cuerpos exhumados se han documentado 25 mujeres.

Hasta la fecha, todas las fosas exhumadas en Extremadura contenían los cuerpos de víctimas de violencia extrajudicial. Para su estudio he clasificado y analizado las fosas comunes en relación con el contexto en el que se produjeron las ejecuciones. Para ello, he definido cuatro categorías de clasificación considerando el contexto de violencia al que pertenecen: (a) la ocupación de los territorios y toma de localidades por parte de las tropas militares sublevadas; (b) ejecuciones producidas tanto en zonas afines al golpe de estado como en las áreas de retaguardia ocupadas tras el paso de las columnas; (c) la represión ejercida tras la finalización de la guerra en los campos de concentración y prisiones; y (d) la lucha de dictadura contra la actividad guerrillera antifranquista ${ }^{33}$. Para mi investigación, he obtenido los datos de la excavación y análisis de fosas comunes en las que se documentaron los restos de 20 mujeres. Dos de los casos descritos en este artículo pertenecen a la categoría (a) y los otros dos a la categoría (b). En el caso

\footnotetext{
${ }^{26}$ Martín Bastos, 2015; Chaves Palacios, 1995.

${ }^{27}$ Martín Bastos, 2015.

28 Chaves Palacios, 2012.

${ }^{29}$ Chaves Palacios, 2012.

${ }^{30}$ Chaves Rodríguez, 2015.

${ }^{31}$ Muñoz-Encinar, 2019b.

32 Martín Bastos, 2015.

${ }^{33}$ Muñoz-Encinar, 2019b, 2016.
} 
de las categorías (c) y (d) no dispongo de datos derivados de la exhumación de fosas comunes. Por lo que en el caso del contexto (c), proporcionaré información basada en fuentes orales y documentales.

La investigación de las fosas comunes se ha llevado a cabo siguiendo las pautas metodológicas y procedimentales de los protocolos de búsqueda e identificación de personas desaparecidas en España, donde intervienen distintas disciplinas científicas. He utilizado los métodos de la antropología forense para obtener el perfil biológico de los individuos localizados en fosas comunes: mediante la estimación de la edad, el sexo y la estatura. Además de obtener un perfil biológico, he realizado el análisis de la violencia perimortem y el tratamiento postmortem de los cuerpos. En cuanto a las fuentes orales, he considerado testimonios publicados por otros autores, recopilados y proporcionados por otros investigadores y reeunidos directamente por mí durante el trabajo de campo. Para las entrevistas he utilizado las pautas específicas que proporciona el «Protocolo de Minnesota» (2016) y el protocolo español elaborado por Francisco Ferrándiz (2010). Además, se ha tenido en cuenta la distorsión de los hechos, las ausencias y los silencios, que a veces forman parte del proceso de memoria y recuerdo mnemotécnico ${ }^{34}$.

La arqueología, nos aporta la información contextual de las fosas comunes, junto al perfil cultural de cada uno de los individuos y su posible relación con otros espacios represivos, en una dimensión cronológica y conductual. La metodología de excavación se ha basado en el principio de unidades estratigráficas de Harris ${ }^{35}$, complementado con el registro y documentación de la distribución espacial de los elementos arqueológicos. En el análisis de las fosas comunes, se ha tenido en cuenta la ubicación del depósito, la secuencia estratiǵráfica, la orientación y disposición de los cuerpos en la fosa y la posición de sus extremidades. Estos datos permiten explorar aspectos como la planificación, la sistematización y la recurrencia en el uso de fosas comunes y paisajes por parte de los perpetradores.

Los cuerpos documentados en el interior las fosas tienen asociados todos aquellos objetos que llevaban consigo en el momento de la muerte, así como los elementos relacionados con al acto represivo que sufrieron, como pueden ser restos de munición u otros objetos asociados a los perpetradores. En función de la tipología a la que pertenecen diferenciamos tres categorías: objetos relacionados con la vestimenta, enseres personales y elementos asociados a los perpetradores. El estudio y análisis de estos objetos nos aporta, en primer lugar, un perfil del individuo al que están asociados. Los elementos que aparecen junto a los cuerpos

\footnotetext{
${ }^{34}$ Ashman 2011; Ricoeur 2004.

${ }^{35}$ Harris, 1991.
} 
están vinculados a la identidad individual, como lo demuestran las formas de vestir, los hábitos personales y la ideología. Al mismo tiempo, los objetos simbolizan identidades colectivas representadas por estatus social, ocupación y género. Hay elementos característicos del género femenino, entre los que se encuentran los asociados a la vestimenta (zapatos de tacón, liǵueros para la sujeción de las medias, etc.), adorno personal (horquillas, pendientes), condición social y creencias (anillos, medallas). Otros, como un kit de costura, dedales o alfileres, reflejan tareas típicas del género femenino en la época. Su presencia y ausencia permiten no solo describir aspectos sobre sus dueños, sino también elaborar posibles propuestas de identificación.

\section{Exhumar la violencia, revelar los rostros}

Tras el fracaso del golpe de estado del 17 de julio de 1936 se inició la conquista de los territorios no controlados por la fuerza. La columna de las tropas rebeldes partió desde Sevilla atravesando Extremadura en dirección a Madrid. En esta campaña fue muy importante el papel que jugó el ejército colonial de África, que llevaba años combatiendo en Marruecos. La guerra colonial que libraron las unidades de ocupación se basó en acciones directas, rápidas y sencillas, y en la obediencia ciega, el desprecio por la vida y la más absoluta cruel$\mathrm{dad}^{36}$. Según el historiador Paul Preston, el uso del terror no fue espontáneo, como se describió explícitamente en las órdenes militares bajo el eufemismo de «castigo». Los soldados y legionarios regulares mutilaron a sus víctimas, les cortaron las orejas, la nariz y los órganos sexuales, y también las decapitaron. Estas prácticas, en combinación con el asesinato de prisioneros y la violación sistemática de mujeres, fueron permitidas por oficiales del ejército rebelde ${ }^{37}$. La visibilidad de las ejecuciones, la exposición de cadáveres y el trato degradante de las víctimas, incluso después de la muerte, tuvieron un impacto psicológico muy fuerte en la población civil y un gran efecto en el establecimiento de un nuevo orden por la fuerza ${ }^{38}$ :

Nuestros valientes legionarios y regulares han enseñado a los rojos que es ser hombre. De paso, también a las mujeres de los rojos, que ahora por fin han conocido hombres de verdad, y no castrados milicianos. Dar patadas y berrear no las salvará... ${ }^{39}$

${ }^{36}$ Espinosa Maestre, 2002.

37 Preston, 2011.

38 Casanova, 2002.

${ }^{39}$ Declaraciones de Queipo de Llano publicadas en Barrios, 1978, p. 205. 
Cuando el ejército rebelde llegó a la provincia de Badajoz se dividió en dos columnas. La primera columna fue enviada hacia la localidad de Mérida y la segunda partió hacia la localidad sudoriental de Llerena. El ejército rebelde encontró una fuerte oposición en Llerena y su ocupación el 5 de agosto de 1936 fue especialmente violenta. Posteriormente, el 31 de agosto, una unidad republicana intentó recuperar la ciudad. Aunque no loǵraron retomar la totalidad de la localidad, consiguieron ocupar temporalmente varios barrios, desestabilizando así las líneas del frente ${ }^{40}$. En los días siguientes, los rebeldes arrestaron a un gran número de personas en la ciudad. Generalmente, las ejecuciones se realizaban en los muros del cementerio. Sin embargo, en este caso, debido a la inestabilidad de la línea del frente y su proximidad con el cementerio, las ejecuciones se llevaron a cabo junto a un arroyo cercano conocido como el Romanzal ${ }^{41}$. Según datos históricos publicados, el número de víctimas entre el 5 de agosto y el 31 de diciembre de 1936 fue de $174^{42} .25$ hombres y diez mujeres fueron ejecutados los días 2 y 8 de septiembre en esta zona $^{43}$.

El 2 de septiembre de 1936, un grupo de civiles, incluidas varias mujeres, fue llevado al arroyo Romanzal al amanecer. Después de su ejecución, los cuerpos de las víctimas fueron apilados y quemados con gasolina, dejándolos expuestos y descubiertos en una fosa común. En la Fosa 1 exhumamos un mínimo de diecinueve individuos de diferentes edades, incluidos siete hombres y cuatro mujeres; en ocho cuerpos no se pudo determinar el sexo. La distribución y orientación de los cuerpos y las extremidades muestra la disposición aleatoria de los cadáveres. Según los testimonios, un sacerdote acudió al lugar con las nuevas autoridades para dar extremaunción a los detenidos. Para ello, colocó un crucifijo frente a cada una de las víctimas para que lo besaran. Cuando el sacerdote pidió a Josefa Fernández Catena, conocida como «La Galla», que besara el crucifijo, ella se negó a hacerlo. En respuesta, el sacerdote le golpeó la boca con la cruz y le rompió los dientes. En este primer grupo de civiles ejecutados en el arroyo Romanzal al menos dos mujeres estaban embarazadas:

La «Galla» tenía los dientes partidos [...] estaba embarazada [...] dijo cuando la iban a fusilar: «no vais a matar a uno, vais a matar dos» ${ }^{44}$.

No sabemos si el niño nació muerto o no. Dijeron que había nacido muerto, pero no supimos nunca ${ }^{45}$.

\footnotetext{
${ }^{40}$ Espinosa Maestre, 2003.

${ }^{41}$ Muñoz-Encinar y Chaves Palacios, 2014.

${ }^{42}$ Martín Bastos, 2015.

${ }^{43}$ Muñoz-Encinar y Chaves Palacios, 2014.

${ }^{44}$ Testimonio de Mary Castilla publicado en Olmedo, 2010a, p. 150.

45 Testimonio de Encarna Ruiz publicado en Olmedo, 2010a, pp. 148-149.
} 
Unos días más tarde y con un mejor conocimiento de la zona, el 8 de septiembre fue enterrado un segundo grupo de víctimas en la misma zona. Los cuerpos fueron colocados en el interior del depósito con la misma orientación, de manera estandarizada y cubiertos con tierra. En este depósito, al que denominamos Fosa 2, documentamos dieciséis individuos de diferentes edades: diez hombres, cinco mujeres y un individuo cuyo sexo no pudo establecerse. Las mujeres fueron enterradas en la parte sur del depósito y fueron las últimas en ser introducidas en la fosa. Esta diferenciación del grupo de detenidos puede estar relacionada con el trato vejatorio perimortem al que eran sometidas las mujeres de forma generalizada, así como con la violencia sexual comúnmente ejercida sobre ellas durante los procesos represivos ${ }^{46}$. Entre los objetos que encontrados junto a cuerpos femeninos documentamos numerosas horquillas, un peine, tres kits de costura, un dedal y un alfiler con una figura religiosa.

Como sucedió en Llerena, las principales ciudades de la zona central y occidental de la provincia fueron ocupadas violentamente durante el verano de 1936. Durante la ocupación, se llevaron a cabo detenciones masivas de forma inmediata. Dentro de estos grupos de detenidos, las personas más significadas de izquierdas fueron eliminadas directamente. Otros detenidos esperaban los avales para garantizar su liberación. Generalmente, aquellos que habían tenido un rol importante dentro del gobierno republicano habían huido antes de la ocupación. Como consecuencia, a menudo eran capturados sus familiares: incluidas numerosas mujeres, hijas, esposas o hermanas de los fugitivos. Al mismo tiempo sus casas fueron saqueadas por los rebeldes de forma sistemática ${ }^{47}$. En algunas ocasiones, la campaña represiva se inició con una ejecución pública y ejemplarizante en la plaza principal del pueblo, tras una misa de campaña ${ }^{48}$. Como ocurrió, por ejemplo, en el pueblo de Fregenal de la Sierra, durante la segunda quincena de septiembre de 1936.

Fregenal de la Sierra se encuentra en la zona suroeste de la provincia de Badajoz. Durante la mañana del 18 de septiembre de 1936, Fregenal fue ocupado por dos columnas militares formadas por 3000 hombres $^{49}$. Según mi investigación, 82 personas fueron ejecutadas entre septiembre de 1936 y diciembre de 1939. Al menos nueve de las víctimas eran mujeres y tres de ellas estaban embarazadas. En la mayoría de estos casos, no existe información documental sobre las mujeres ejecutadas y sus muertes nunca fueron registradas. En algunos casos, el conocimiento de los apellidos se ha desvanecido en la memoria colectiva y solo se recuerdan los nombres o apodos de las víctimas. Muchas mujeres fueron vejadas física y psicoló-

\footnotetext{
${ }^{46}$ Richards, 1999; Preston, 2011.

${ }^{47}$ Vega Sombría, 2011.

48 Espinosa Maestre, 2002.

49 Espinosa Maestre, 2003.
} 


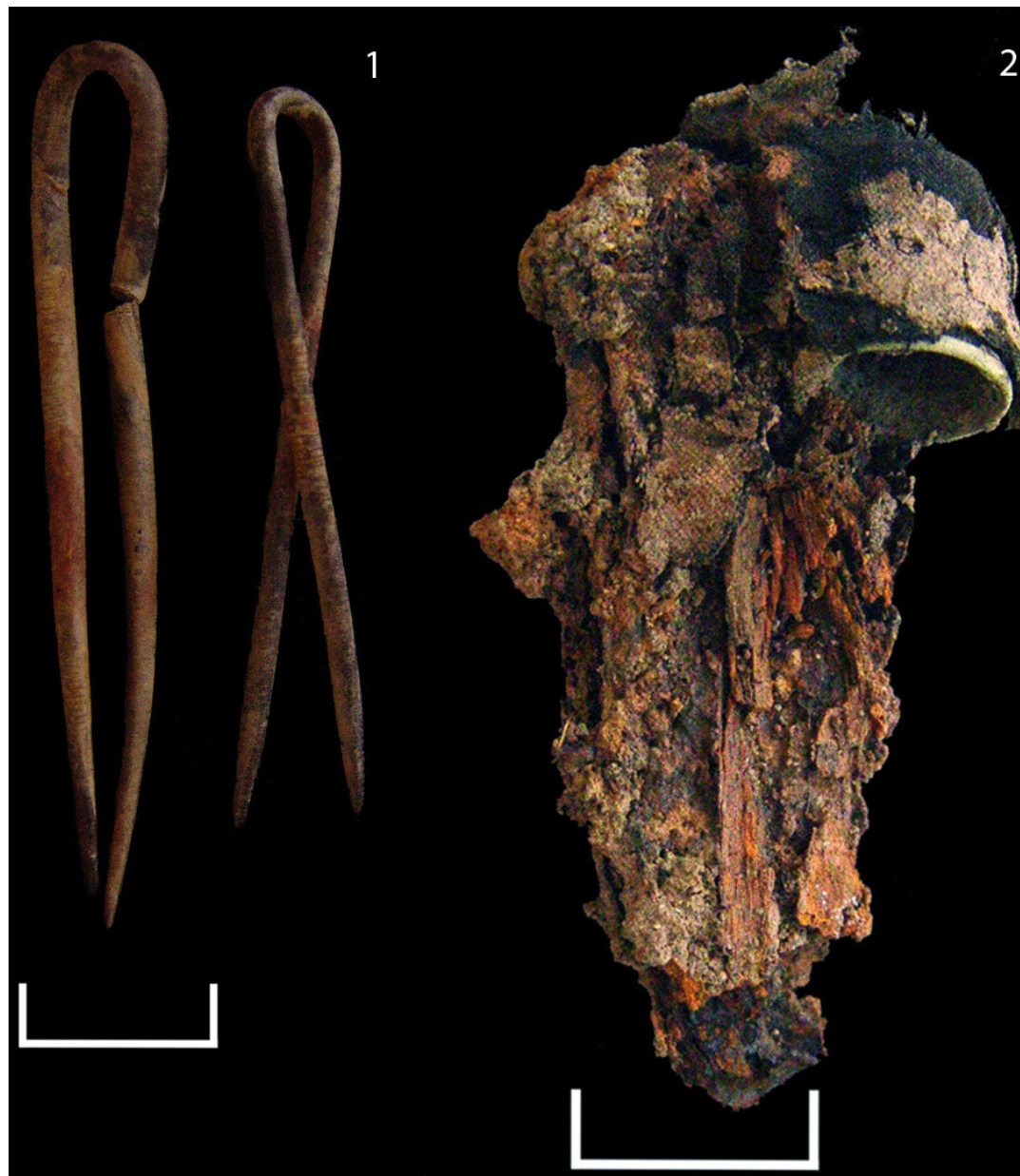


gicamente, castigadas a realizar tareas para las fuerzas militares, rapadas y expuestas públicamente después de haber ingerido aceite de ricino. Los testimonios orales relatan el abuso sexual y las violaciones sufridas por muchas mujeres:

Mi hermana la chica pobrecita judicaron [la violaron] con ella y conmigo y con mi otra hermana... nos... raparon $[. .$.$] me dieron aceite de ricino [...] sufrí$ mucho $[\ldots]$ por ser mi hermano socialista [...] castigaron a toda la familia [...] eso fue el peor castigo ${ }^{50}$.

La mayoría de las ejecuciones se llevaron a cabo en el cementerio del pueblo, donde el sepulturero se encargaba de enterrar los cadáveres. En este cementerio exhumamos siete fosas comunes y documentamos los cuerpos de 43 víctimas, siete de ellas mujeres. Una de las mujeres exhumadas se encontraba en avanzado estado de gestación en el momento de ser ejecutada. Durante la excavación, en su pelvis, documentamos los restos óseos de un feto de entre 7 y 9 meses. Todos los cuerpos habían sido enterrados siguiendo el mismo procedimiento, colocados en decúbito supino, con orientaciones alternas, con las extremidades inferiores y superiores en paralelo. Según las fuentes orales, hubo al menos un grupo de represaliados formado únicamente por mujeres. Sin embarǵo, en las campañas de exhumación realizadas hasta el momento, todas las fosas comunes excavadas contenían los cuerpos de hombres y mujeres.

La Venta ahí cerca del cementerio [...] pues ahí metieron a cinco o seis muchachas jóvenes y judicaron [las violaron] con ellas también porque vimos nosotros sangre y de to y aluego las llevaron y las enterrarían, pero judicaron antes con ellas porque eso se sabía ${ }^{51}$.

Una de las mujeres era Antonia Regalado Carballar conocida como «la Chata Carrera» que tenía 22 años cuando fue ejecutada. El trato denigrante que sufrió Antonia antes y después de la muerte ha pasado a formar parte de la memoria colectiva traumática del pueblo, y ha sido narrado por múltiples testimonios, debido a los crueles detalles aportados por el sepulturero:

Le puso a un hombre debajo [del cuerpo de] mi tía encima y el otro hombre penetrándola por encima, uno por debajo y uno por encima [...] «va a quedar satisfecha» [...] se lo contó el tío disfrutando, a carcajadas limpias [...] la hicieron corretear por todo el cementerio abusaron de ella y después la mataron y luego la enterró este señor la enterró así y le dijo: así como una puta la hemos enterrao ${ }^{52}$.

${ }^{50}$ Testimonio de Fregenal de la Sierra, anonimizado para proteger a la víctima. Recogido por Zahira Aragüete Toribio y transcrito por la autora.

51 Testimonio de José Vázquez López. Recogido y transcrito por la autora.

52 Testimonio de Fregenal de la Sierra, anonimizado para proteger a la víctima. Recogido y transcrito por la autora. 
En la Fosa 2 de Fregenal de la Sierra, documentamos los cuerpos de dos hombres y una mujer enterrados superpuestos en posición supina. La mujer fue colocada entre los cadáveres de los hombres con la cabeza orientada hacia el oeste, mientras que los hombres fueron orientados hacia el este. Esta mujer tenía asociados algunos botones relacionados con su ropa y una única liǵa para la sujeción de las medias. Esta mujer tenía entre 35 y 40 años al momento de su muerte y, datos que no se corresponden con los de Antonia Regalado, por lo que permanece sin identificar por el momento. El caso de «la Chata Carrera» o la mujer no identificada de la Fosa 2 muestran que la humillación de las víctimas a veces no terminaba con la muerte y la deshumanización del enemigo continuó en la fosa ${ }^{53}$. Las mujeres exhumadas de las fosas de Fregenal de la Sierra llevaban consigo elementos característicos de la indumentaria femenina como zapatos de tacón, ligas, botones y gemelos de nácar, entre otros. Una de ellas incluso conservaba parte de un vestido. Además, también documentamos varios pendientes, entre ellos uno de oro formado por dos círculos de diferentes tamaños con piedras incrustadas formando una figura floral y un par de pendientes con piedras verdes talladas.

Según datos históricos y arqueolóǵicos, las ejecuciones llevadas a cabo en Fregenal de la Sierra fueron materializadas mayoritariamente sobre la población masculina, ya que había sido un sector fuertemente luchador desde la esfera política y sindical en la zona. No obstante, hoy sabemos que existió también un gran número de mujeres ejecutadas y vejadas que, al igual que el género contrario, habían tenido una clara implicación política durante la Segunda República y habían luchado por la liberación de la mujer en todos los ámbitos de la vida cotidiana: el hogar, la familia, el trabajo, la política y en definitiva la sociedad. Alǵunas de estas mujeres, como «la Chata Carrera», fueron vistas como mujeres de bandera. Según testimonios orales, «la Chata Carrera» solía montar a caballo proclamando el advenimiento de la revolución social y la liberación de la mujer de la opresión. Otras mujeres jóvenes se organizaron para exiǵir la mejora de sus condiciones laborales y su situación personal. Algunos de ellas fueron fieles compañeras de importantes personalidades políticas locales. Todas estas mujeres habían visto con sus propios ojos los cambios que la Segunda República había traído a la feminidad, sin tener que abandonar ni supeditar por ello su propia condición y género. Sin embargo, todas vieron frustradas sus luchas y expectativas, así como los frutos de su esfuerzo, enterrados junto a la Segunda República en las fosas comunes del cementerio de Fregenal de la Sierra.

Mientras las tropas rebeldes ocupaban el centro y el oeste de Extremadura, el norte de la región manifestó su apoyo al levantamiento militar durante los

\footnotetext{
${ }^{53}$ González-Ruibal, 2020; Muñoz-Encinar, 2019a.
} 


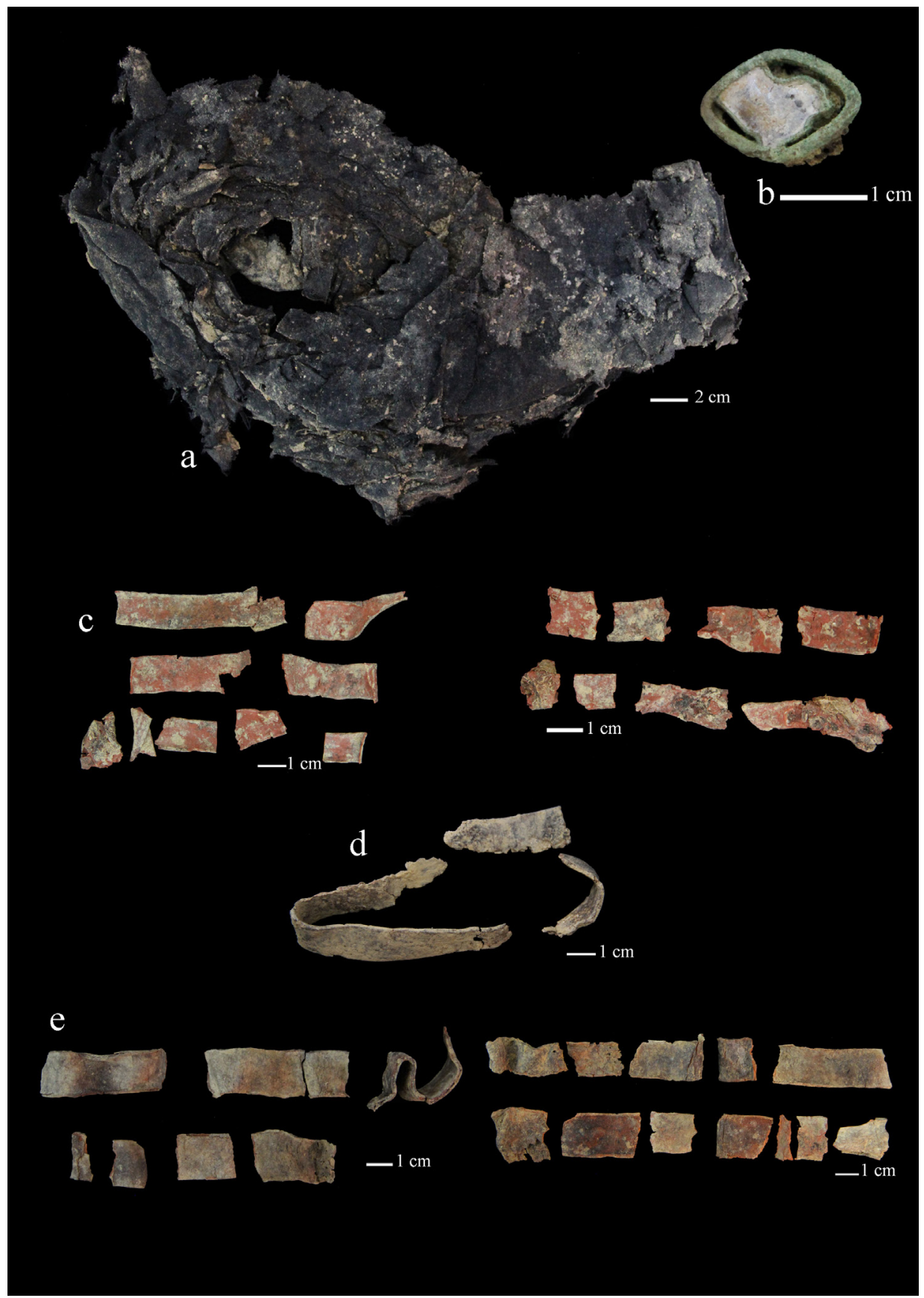

Figura 2. Objetos encontrados junto a los cuerpos de mujeres exhumadas en las fosas comunes del cementerio de Fregenal de la Sierra: a) Manga de un vestido; b) Gemelos con figura de pájaro; c) Ligas para sujeción de las medias; d) Liga para sujeción de las medias; e) Ligas para sujeción de las medias. Autor: Laura Muñoz-Encinar (․ 


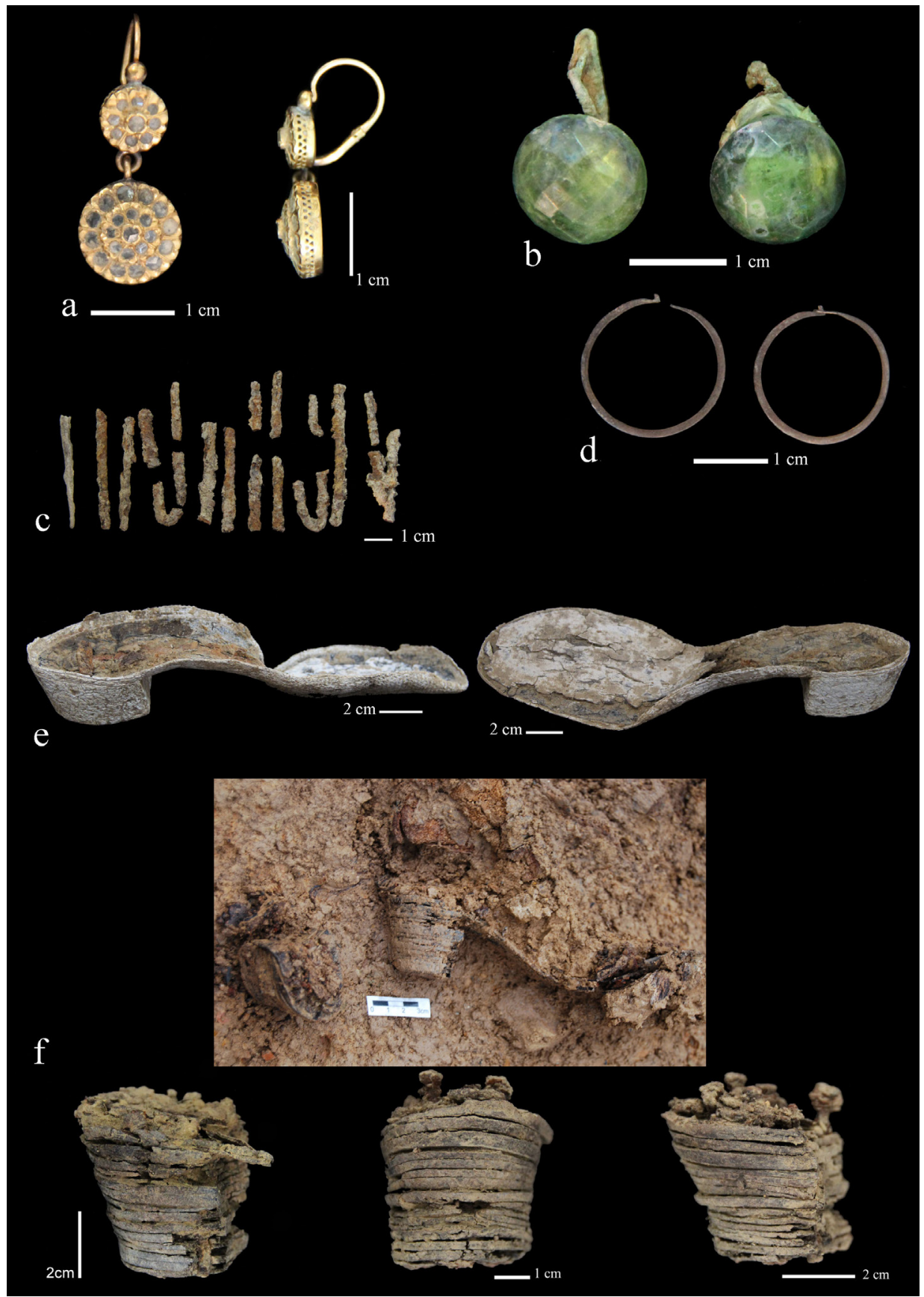

Figura 3. Objetos documentados junto a los cuerpos de mujeres exhumadas en las fosas comunes del cementerio de Fregenal de la Sierra a) Pendiente de oro; b) Pendientes; c) Horquillas d) Pendientes e) Zapatos de tacón f) Zapatos de tacón. Autor: Laura Muñoz-Encinar @ 
primeros días del golpe. Tras la disolución de los ayuntamientos, grupos paramilitares como Falange y la Guardia Civil controlaron las principales localidades ${ }^{54}$. Las prácticas represivas desarrolladas en estas áreas se conocen como paseos o sacas. Estas prácticas, que también existían en el resto de España, implicaban la detención y ejecución de una selección concreta de personas o grupos de civiles que habían estado involucrados en actividades políticas o habían mostrado simpatía por la República. Dentro de la práctica de los paseos, las víctimas generalmente eran arrestadas en sus casas con la justificación ir a declarar. Posteriormente, en algunas ocasiones, pasaban de forma temporal por cárceles improvisadas donde eran interrogadas, registradas, torturadas, humilladas y finalmente ejecutadas. En otros casos, las víctimas eran sacadas de sus casas y ejecutadas directamente ${ }^{55}$. Unas detenciones que se realizan de forma irregular, sin expedientes ni trámites de ningún tipo. En estas prácticas represivas el uso de los represaliados como parte de la propaganda del terror se va a centrar principalmente en las torturas públicas practicadas antes de la muerte. De este modo se generalizaron las vejaciones y martirios de las víctimas, que antes de ser pasadas por las armas fueron humilladas, torturadas y mutiladas como mecanismo de escarnio público. El movimiento de víctimas de una localidad a otra para ser ejecutadas, con la intención de hacer desaparecer las víctimas e infundir el terror sobre la población, fue también parte de la estrategia represiva desatada por los sublevados. Un procedimiento generalizado posteriormente en las dictaduras latinoamericanas ${ }^{56}$. De esta forma, las familias ignoraban los detalles de la desaparición de sus seres queridos, incluida la ejecución y el paradero final de sus cadáveres. El término sacas se refiere al arresto de personas, que fueron encarceladas y luego sacadas de la cárcel en grupos para ser asesinadas. En esta práctica represiva se incluyó también a mujeres debido a su implicación política, por haber transgredido el modelo patriarcal femenino tradicional o como consecuencia de los lazos familiares.

Villasbuenas de Gata es un pequeño pueblo situado al norte de la provincia de Cáceres. Esta zona, como otras en Cáceres, manifestó su apoyo a los sublevados en los primeros días del levantamiento militar. En Villasbuenas, cuatro hombres fueron ejecutados junto a otras víctimas procedentes de localidades vecinas ${ }^{57}$. Las víctimas fueron asesinadas en varios lugares en las cunetas de las carreteras que conducían al pueblo. En una de estas áreas, llamada «La Charca de la Gitana», hallamos dos fosas individuales donde fueron enterrados un hombre y una mujer.

\footnotetext{
${ }^{54}$ Chaves Palacios, 1995.

55 Preston, 2011.

${ }^{56}$ Funari y Zarankin, 2006; Preston, 2011.

${ }^{57}$ Chaves Palacios, 1995.
} 
La mujer era Isabel conocida como «La Cubana» y el hombre era Justo Roma Salvador, ambos originarios del cercano pueblo de Gata. Isabel había estado en Cuba, de ahí su apodo. Cuando regresó a España, tenía una buena posición económica y abrió una tienda en el pueblo de Gata, ejerciendo también de prestamista en la zona. Según lo que sabemos de Isabel, era una mujer con ideales de izquierda, casada con Marcelo Domínguez Solís, aunque hasta el día de hoy, nadie recuerda su apellido. Su marido fue ejecutado y enterrado posteriormente en el cementerio de la aldea de El Payo (Salamanca). Durante la excavación, asociados al cuerpo de Isabel, solamente documentamos algunos enganches de metal relacionados con la ropa, un alfiler y unas horquillas para recoger el cabello en un moño. Alǵunos testimonios indican que fue obligada a mantener relaciones sexuales con la otra víctima antes de ser ejecutada, como parte del trato vejatorio antes de la muerte, asesinada finalmente de un tiro en el cráneo.

La práctica represiva de paseos o sacas, implementada por los rebeldes en las zonas que apoyaron el golpe de estado y en las zonas de la retaǵuardia, alcanzó su punto álgido de perfeccionamiento en los enclaves que hemos definido como parajes del terror ${ }^{58}$. El procedimiento represivo pasará de ser aplicado individualmente a constituir un modelo de ejecución masiva de personas, tanto en Extremadura como en el resto de las zonas ocupadas del país. Estos lugares solían estar ubicados en las afueras de las aldeas y se utilizaron de forma sistemática para realizar ejecuciones durante la Guerra Civil. Las fosas exhumadas en el lugar conocido como «Los Arenales», entre las localidades de Miajadas y Escurial (Cáceres), así como los enclaves similares diseminados por toda la geografía del Estado corresponden a esta estrategia represiva ${ }^{59}$. Según datos publicados, más de un centenar de personas fueron ejecutadas en la zona, de las cuales al menos 24 , incluidas seis mujeres, fueron enterradas en «Los Arenales ${ }^{60}$. Durante el verano de 1936 a este lugar fueron trasladados camiones con civiles detenidos en los poblados aledaños. Posteriormente asesinados y enterrados en fosas comunes en el mismo paraje ${ }^{61}$. Aurelia Juárez Gómez y su hija María Fácila Juárez se encontraban entre las víctimas. María estaba casada con Macario Muñoz Gallego, obrero y conocido izquierdista de la zona. Tras el golpe, Macario huyó a la zona republicana por temor a posibles represalias. Cuando escapó, ambas mujeres fueron arrestadas y encarceladas en Miajadas. Desde allí fueron llevadas en camión $\mathrm{a}$ «Los Arenales» donde fueron ejecutadas junto a otras personas ${ }^{62}$.

\footnotetext{
${ }^{58}$ Muñoz-Encinar y Chaves Palacios, 2014.

${ }^{59}$ González-Ruibal, 2014.

${ }^{60}$ Chaves Palacios, 1995.

${ }^{61}$ Muñoz-Encinar y Rodríguez-Hidalǵo, 2010.

${ }^{62}$ Olmedo, 2010b.
} 
En «Los Arenales», localizamos y exhumamos dos fosas comunes que contenían siete y nueve cuerpos respectivamente. En el depósito que denominamos Fosa 1 se recuperaron un mínimo de siete individuos. En la Fosa 2 documentamos un total de nueve individuos -seis hombres y tres mujeres, todos de edad adulta-. La secuencia de acumulación de los cuerpos muestra una distribución diferencial de los individuos en cuanto al género. Los individuos de sexo masculino fueron los primeros en ser introducidos en la fosa, depositados en la zona central y este, dispuestos de manera longitudinal al depósito con la cabeza orientada hacia el este. En cambio, los individuos femeninos están colocados en la zona oeste de la fosa de manera longitudinal y oblicua al eje del depósito, con la cabeza hacia el oeste, siendo los cuerpos de estas mujeres los últimos en ser introducidos en la fosa ${ }^{63}$. Las diferencias en el patrón general de disposición y ordenamiento de los cadáveres en relación con su género pueden interpretarse como una forma de diferenciar el grupo de detenidos por parte del pelotón de fusilamiento. Esta diferenciación puede estar asociada a prácticas perimortem relacionadas con la humillación de las víctimas. Dos de estas mujeres presentaban, además, lesiones perimortem en los brazos relacionadas con traumatismos de tipo contuso. Estos aspectos pueden guardar relación con los distintos procesos vejatorios perimortem sufridos por las víctimas de género femenino. Ello podría estar asociado a la violencia sexual sufrida por las víctimas de manera generalizada dentro de este tipo de procesos represivos. A partir de los restos munición podemos inferir que la ejecución de las víctimas se llevó a cabo in situ mediante disparos con fusiles Mauser, que era el armamento reǵlamentario del ejército sublevado de la época. Posteriormente se les dio el tiro de ǵracia con una pistola. La mayoría de las víctimas no tenían numerosos objetos asociados, tal vez por su bajo poder adquisitivo o quizás porque les fueron sustraídos durante el encarcelamiento. El cuerpo de una de las mujeres tenía asociados dos pendientes de oro y un anillo de plata con las iniciales AM.

Desde los últimos meses de 1936 y hasta el verano de 1938, la actividad militar en el frente Extremadura fue de baja intensidad ${ }^{64}$. En julio de 1938, sin embargó, se llevó a cabo una nueva ofensiva rebelde que provocó la pérdida de la mayor parte del territorio que permanecía bajo el gobierno republicano. Castuera es una localidad situada en la zona oriental de la provincia de Badajoz. Tras el levantamiento militar, se mantuvo fiel a la República y se convirtió en la capital republicana de Extremadura hasta su caída el 23 de julio de 1938. Tras la ocupación militar se inauguró una fase de terror y violencia similar a la vivida por otras localidades durante el verano de 1936. Las primeras acciones violentas están

\footnotetext{
${ }^{63}$ Muñoz-Encinar y Rodríguez-Hidalgo, 2010.

${ }^{64}$ Chaves Palacios, 1997.
} 


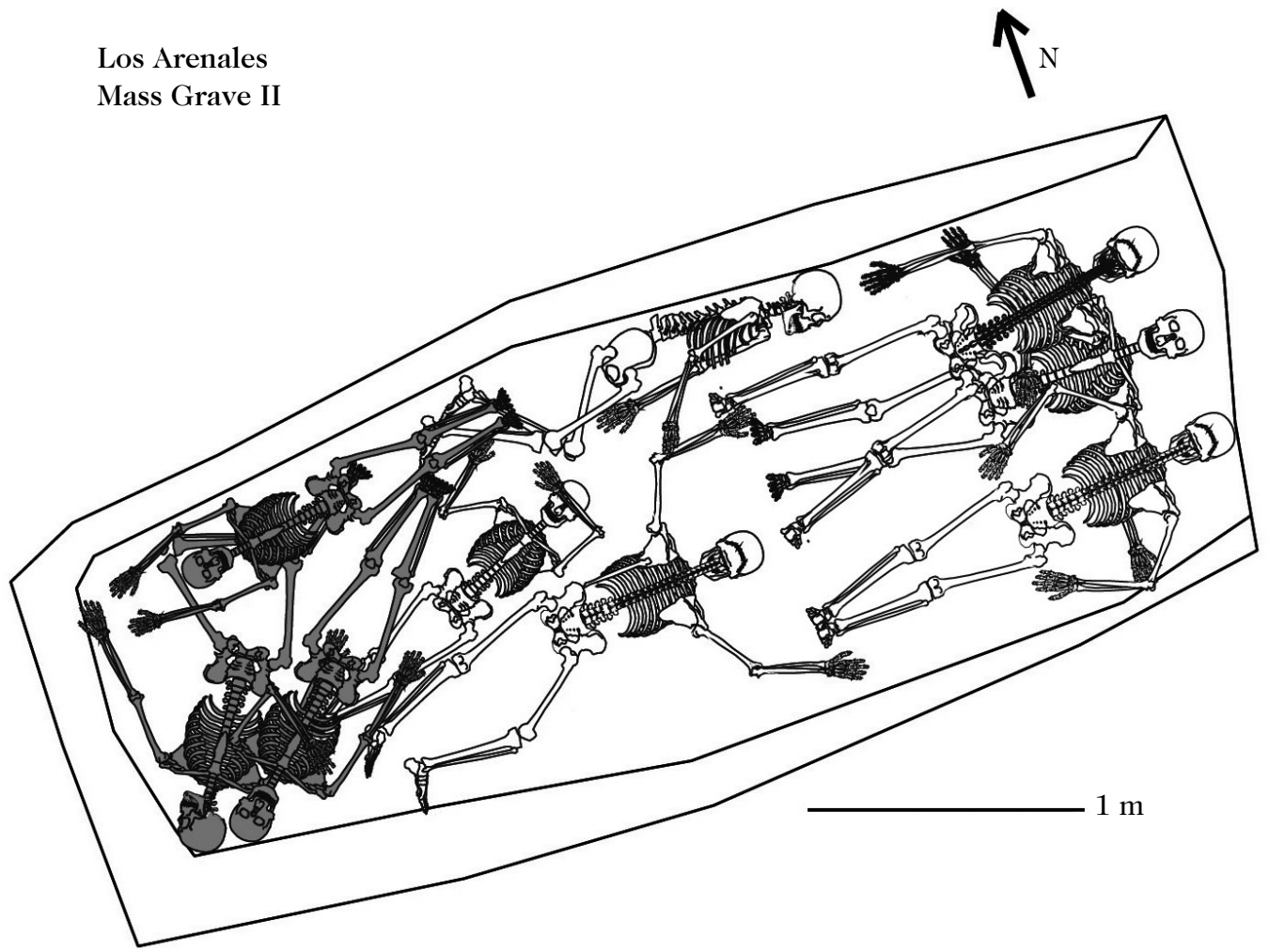

Figura 4. Dibujo de la Fosa Il de "Los Arenales». El color gris se corresponde con los cuerpos de las mujeres. Autor: Laura Muñoz-Encinar $\odot$.

marcadas en la memoria colectiva de la población por la violación y asesinato de cinco mujeres, de las que no existe información documental y sus nombres han sido olvidados. Tras la ocupación militar se inició de forma inmediata la detención sistemática de todas aquellas personas que habían apoyado a la República. Los prisioneros fueron confinados en varias cárceles, segregados en función del género, y las ejecuciones comenzaron de forma inmediata en el cementerio municipal y las zonas aledañas ${ }^{65}$. Los cuerpos fueron enterrados en fosas comunes en el interior del cementerio. No obstante, a pesar de los esfuerzos realizados, no hemos podido localizarlos y recuperarlos hasta la fecha ${ }^{66}$.

Una de las primeras ejecuciones llevadas a cabo en Castuera fue la de Carolina Haba García, que estaba casada con José Sayabera Miranda. José era miembro

${ }^{65}$ López-Rodríguez, 2009.

${ }^{66}$ Muñoz-Encinar, Ayán y López-Rodríguez, 2013. 
del Partido Comunista y se alistó en el Ejército Republicano con tres de sus hijos. En 1938 fue consejero de la Diputación Provincial Republicana, y también fue autor de varios artículos publicados en la revista Extremadura Roja. La familia Sayabera-Haba tuvo nueve hijos y ante la inminente ocupación de Castuera la mayor parte de la familia huyó en una evacuación masiva de la población civil hacia la zona republicana. Carolina no tuvo tiempo de huir y se quedó atrapada en Castuera con una de sus hijas. Tras la toma del pueblo por las tropas sublevadas Carolina fue arrestada. Desde la prisión, fue trasladada al cementerio y ejecutada con un grupo de civiles a finales del mes de julio ${ }^{67}$. Una vez finalizada la guerra, su marido y otros cuatro miembros de su familia también fueron ejecutados.

Al finalizar la guerra se inició la segunda fase represiva caracterizada por la detención de miles de soldados republicanos, así como una gran cantidad de población civil que regresaba a sus zonas de origen tras la finalización del conflicto $\operatorname{armado}^{68}$. Numerosos civiles fueron arrestados nada más regresar a la localidad en la estación de tren. Este fue el caso de Matilde Morillo Sánchez, quien estuvo casada con Antonio Navas Lora, militante del Partido Socialista e importante activista político. Matilde era maestra y había participado activamente en las comisiones pedagógicas que formaron parte de la reforma educativa llevada a cabo durante la Segunda República. Creía en la necesidad de emancipar a la mujer a través de la cultura y consideraba la educación uno de los pilares fundamentales para la transformación de la sociedad:

Volvimos en un tren de ganado [...] cuando llegamos a la estación de Castuera había allí muchos falangistas yo veía las botas, las pistolas [...] ella fue identificada $[\ldots]$.

Dicen que la violaron delante de la iglesia [...] también dicen que la llevaron al cementerio y que allí en la sala de autopsias siguió la orgia [...] al amanecer volvían los asesinos en el volquete que los habían llevado y en el fusil llevaban el abrigo de rizo de mi madre, como una bandera como un trofeo ${ }^{69}$.

En el caso de Matilde existe un claro proceso de ocultación de la represión en la documentación oficial, extensible a otros tantos casos víctimas de la «Justicia de Franco». En los archivos de Matilde no hay ninguna información sobre el momento en que ingresó en la cárcel de Castuera ni cuando salió. En 1946, un juez militar ordenó su liberación, arǵumentando que no encontró motivos para procesarla. Sin embargoo, Matilde ya había sido ejecutada sin juicio siete años antes.

${ }^{67}$ López-Rodríguez, 2009.

${ }_{68}$ Muñoz-Encinar, Ayán y López-Rodríguez, 2013.

${ }^{69}$ Testimonio de Aurora Navas Morillo hija de Matilde Morillo y Antonio Navas, recogido y trascrito por la autora. 


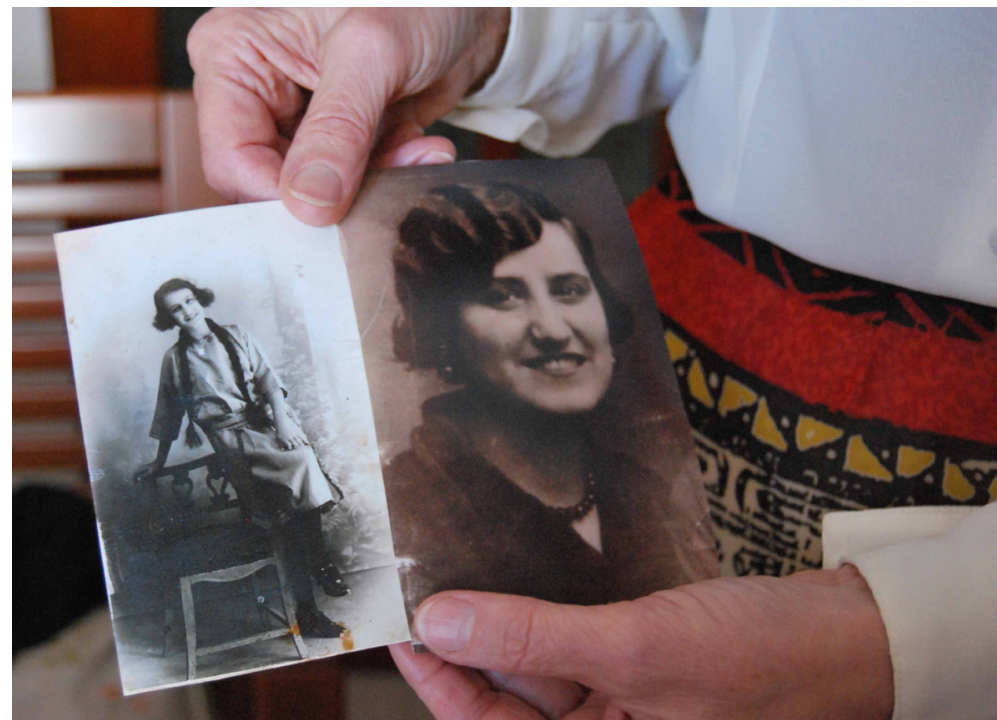

Figure 5. Fotografías de Matilde Morillo Sánchez sujetadas por su hija Aurora Navas Morillo. Fotografía realizada durante la entrevista realizada en Castuera en 2011. Autor: Laura MuñozEncinar ().

El ocultamiento de información también es evidente en el documento utilizado para registrar su muerte. El documento muestra que se registró tres años después de su ejecución, con una fecha y una causa de muerte falsa: como «resultado de acciones de guerra, fuera de las murallas de esta localidad».

Aquellas zonas de la provincia de Badajoz que permanecieron bajo control republicano hasta el final de la guerra comenzaron a ser ocupadas a finales de marzo de 1939. Es en ese momento cuando la población de Puebla de Alcocer es ocupada por las tropas franquistas y se produce la detención de los vecinos más significados políticamente. Los presos fueron separados según su género en diferentes cárceles, así como en un campo de concentración, ubicado en las afueras de la ciudad. Según los resultados de las exhumaciones, 42 hombres fueron ejecutados y enterrados en cinco fosas comunes durante el mes de mayo de 1939. La única mujer asesinada en el pueblo fue María Quiteria, de la que no existe información documental sobre el proceso represivo que sufrió ni tan si quiera registro de su muerte. En Puebla de Alcocer, otras trece mujeres fueron detenidas y procesadas en consejo de guerra, condenadas a distintas penas y enviadas a diferentes centros penitenciarios del país ${ }^{70}$. Además, un gran número de mujeres

${ }^{70}$ Chaves Rodríguez, 2015. 
fueron rapadas y paseadas por las calles de la localidad tras ser obligadas a ingerir aceite de ricino. María, costurera y bordadora profesional, había sido novia de Eugenio Muga Ruiz, alcalde republicano y presidente del Comité Local de Defensa de la República del pueblo, con quien tuvo una hija que falleció a los 2 años. Tras la ocupación del pueblo, María fue acusada de bordar la bandera republicana, arrestada y encarcelada. Según testimonios orales, durante el tiempo que estuvo encarcelada sufrió torturas físicas y psicológicas y varios paramilitares locales intentaron violarla. Integrantes de los grupos paramilitares locales se enteraron de su posible liberación y decidieron llevarla al cementerio local para matarla. Cuando llegaron al cementerio, las fuerzas militares se negaron a disparar contra María Quiteria y finalmente fue un escuadrón paramilitar el que llevó a cabo la ejecución. Sobre la historia de la ejecución de María Quiteria existe un recuerdo persistente, ahora convertido en leyenda, en la memoria traumática colectiva de la sociedad local. Dos años después del asesinato de María Quiteria, su compañero, Eugenio Muga Ruiz, fue sometido a consejo de guerra y acusado de adhesión a la rebelión, condenado a muerte y ejecutado el 9 de mayo de 1941.

\section{Conclusiones: la violencia de género durante la Guerra Civil y la dictadura franquista en España}

Desde la Antigüuedad las mujeres han sido víctimas de todo tipo de violencia sexual durante y después de las guerras ${ }^{71}$. La violencia de género se ha estudiado en múltiples escenarios de conflicto de los siǵlos XX y XXI, como Japón y Alemania después de la Segunda Guerra Mundial ${ }^{72}$, la ex Yugoslavia ${ }^{73}$, Ruanda ${ }^{74}$, El Salvador, Honduras, Nicaragua, Perú ${ }^{75}$ y Guatemala ${ }^{76}$ entre otros.

En el caso español, la represión ejercida contra la población civil tras el golpe de julio de 1936 no se limitó a los hombres, y numerosas mujeres fueron víctimas de violencia física y psicológica ${ }^{77}$. Documentos, discursos militares, transmisiones de radio, testimonios y la presencia de mujeres en fosas comunes son testigos de la violencia de género extremadamente brutal puesta en práctica por las fuerzas rebeldes militares y paramilitares durante la Guerra Civil y la dictadura franquista ${ }^{78}$. Los datos rela-

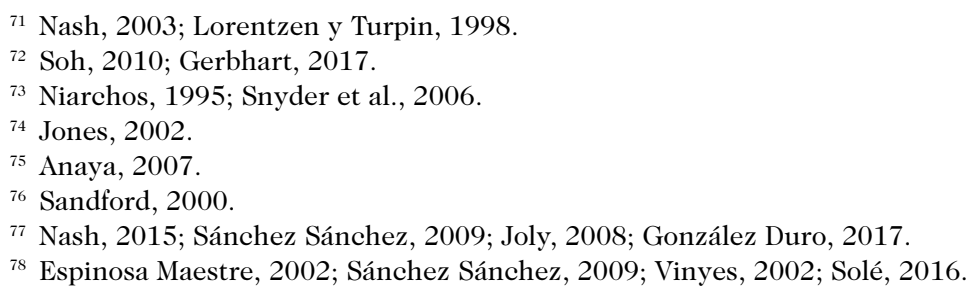


cionados con la violencia de género aportados por las fuentes orales y documentales son consistentes con los resultados de la investigación en las fosas comunes, lo que nos ofrece nuevas oportunidades para examinar las formas específicas de represión sufridas por las mujeres durante la Guerra Civil española. Este enfoque multidisciplinar, que combina historia oral, historia documental, arqueología y antropología forense, puede ser relevante además en el estudio de otros conflictos similares.

En relación con la arqueología, los elementos materiales asociados a los cuerpos nos aportan una gran información sobre la identidad individual, colectiva y cultural de las víctimas ${ }^{79}$. Las pertenencias y enseres personales registrados en fosas comunes incluyen aspectos relacionados con actividades e identidades profesionales relacionadas con la mujer. Alǵunos objetos representan el lado más íntimo de sus dueños y al mismo tiempo sus creencias más profundas, como es el caso de los elementos religiosos. Estos mismos elementos valorados de manera conjunta nos muestran la homogeneidad o no del grupo de represaliados, así como la posible procedencia y contexto social y político al que pertenecen.

Los datos arqueológícos también permiten realizar inferencias acerca de la forma y contexto en que se desarrolló la represión. En varias fosas comunes, documentamos pendientes de valor que revelan, por un lado, el nivel socioeconómico de sus dueñas y, por otro, que las víctimas no fueron registradas de forma sistemática ni los cadáveres saqueados. En el caso de Fregenal de la Sierra, las mujeres halladas en las fosas comunes llevaban zapatos de tacón, medias, ligueros, botones de nácar, gemelos y un vestido de manǵa larǵa. Estos elementos que son característicos de las mujeres nos indican a su vez que los asesinatos no ocurrieron durante el verano.

La presencia de ciertos objetos nos arroja luz sobre lo sucedido en el pasado, pero su ausencia también puede revelar información importante ${ }^{80}$. Por ejemplo, a algunas mujeres de las fosas comunes de Fregenal les faltaban algunos elementos de la ropa y joyas: una mujer apareció con una única liga y otra parecía haber perdido un pendiente de oro. La ausencia de estas pertenencias personales está probablemente relacionada con el proceso represivo y es plausible que se perdieran durante el maltrato al que fueron sometidas antes de ser asesinadas, en el que el abuso sexual fue recurrente ${ }^{81}$. Como se ha mencionado con anterioridad, la ejecución de mujeres republicanas tuvo un importante significado simbólico como parte de la campaña represiva ejercida por los sublevados. En este sentido, algunos efectos personales, como en el caso del abrigo de Matilde Morillo en Castuera, pudieron ser sustraídos a las víctimas y utilizados como trofeo por los perpetradores.

\footnotetext{
${ }^{79}$ Muñoz-Encinar, 2019a.

${ }^{80}$ Muñoz-Encinar y Chaves Palacios, 2014.

81 Richards, 1999; Preston, 2011.
} 
La distribución y orientación de los cuerpos dentro de las fosas ha evidenciado diferencias en función del género, que pueden estar relacionadas con el tratamiento vejatorio perimortem sufrido por las mujeres, y en el que la violencia sexual suele jugar un papel muy destacado dentro del proceso represivo ${ }^{82}$. Las mujeres suelen aparecer en un área específica de la fosa común y son las últimas en ser enterradas. El trato vejatorio de las víctimas, en ocasiones, continuó tras la ejecución como parte del proceso de deshumanización del enemigo después de la muerte $^{83}$. La aproximación al conocimiento del proceso represivo puede, además, incrementarse sustancialmente mediante el análisis de la violencia perimortem y los patrones de lesión observados en las víctimas.

Es especialmente significativa la presencia de varias mujeres embarazadas asesinadas en Llerena y Freǵenal de la Sierra. Una constante que los testimonios orales señalan en multitud de lugares a lo largo de todo el país ${ }^{84}$. El caso de la mujer embarazada exhumada en Fregenal de la Sierra es uno de los escasos casos documentados arqueológicamente en España, ya que raras veces se conservan restos fetales ${ }^{85}$. La ejecución de mujeres embarazadas es, sin embargó, paradiǵmática de las contradicciones presentes en la ideología franquista, especialmente si consideramos que fue permitida por el régimen, mientras que su ideología nacionalcatólica se oponía fuertemente al aborto ${ }^{86}$. La represión de mujeres embarazadas no solo ocurrió durante la guerra, sino que también se materializó durante la dictadura en las cárceles de $\mathrm{Franco}^{87}$.

Las mujeres activistas antifascistas fueron homogeneizadas y estigmatizadas como rojas y suponían para el Franquismo la decadencia moral y la pérdida de los valores católicos ${ }^{88}$. La violencia específica ejercida sobre el cuerpo de las mujeres fue concebida con fin purificador del Franquismo y la política de deshumanizar a las mujeres antifascistas ${ }^{89}$. Las rojas representaban simbólicamente a la Segunda República, junto a todos aquellos valores de anti-España y de decadencia moral. Castigadas por actuar de forma impropia a su género hasta el punto de que roja adquirió el significado de no-mujer ${ }^{90}$, siendo consideradas por ideólogos del Franquismo como Vallejo Nájera como seres inferiores, convencidos de su perversidad innata y criminalidad natural ${ }^{91}$. Perseguidas de manera continua, las mujeres fueron

\footnotetext{
82 Richards, 1999; Preston, 2011.

83 González-Ruibal, 2020; Muñoz-Encinar, 2019a.

${ }^{84}$ Rodrigo, 2008; Espinosa Maestre, 2003; Ferrándiz, 2014.

${ }^{85}$ González-Ruibal, 2020, p. 24

${ }^{86}$ Nash, 2015; Moreno, 2013; Sánchez Sánchez, 2009.

${ }^{87}$ Rodrigo, 2008.

88 Nash, 2015.

${ }^{89}$ Nash, 2013.

90 Sánchez Sánchez, 2009.

91 Vallejo-Nájera, 1939.
} 
objeto de un castigo doble, por la transǵresión moral a las normas de género del ideal de domesticidad y sumisión femenina, así como por su compromiso antifascista ${ }^{92}$. La ejecución de mujeres respondió a una estrategia diferente a la represión ejercida sobre el género masculino. Lejos de un intento de ser aniquiladas, los castigos aplicados a las mujeres estuvieron centrados en la ejemplaridad y de ahí su fuerte componente simbólico, materializado tanto en la crueldad extrema utilizada como en la selección de las víctimas y en el tratamiento de sus cuerpos, vivos y muertos ${ }^{93}$.

En conclusión, las mujeres fueron humilladas y utilizadas como símbolo de un lenguaje plurisignificativo: «La mujer considerada como un cuerpo, un territorio donde el hombre proyecta sus deseos de victoria o de dominio, por lo que el ejercicio de la represión hace visible simultáneamente en un solo gesto la victoria de los vencedores y el sometimiento de $l o s$ vencidos ${ }^{94}$. En las guerras a lo largo de la historia, así como en el caso de la Guerra Civil española y la dictadura de Franco, las mujeres han sido víctimas de todo tipo de actos de violencia sexual, siendo utilizadas como un arma de guerra y usando la violación de sus cuerpos para aterrorizar y castigar a los enemigos.

\section{Bibliografía}

Anaya, Noemy, Monitoreo sobre violencia sexual en conflicto armado: Colombia, El Salvador, Guatemala, Honduras, Nicaragua y Perú, Lima, Comité de América Latina y el Caribe para la defensa de los derechos de la mujer, 2007.

Assmann, Aleida, Cultural Memory and Western Civilization: Functions, Memory, Archives, New York, Cambridge University Press, 2011.

Baquero, Miguel Ángel, Que fuera mi tierra. Anuario 2015. Intervenciones en fosas comunes del franquismo en Andalucía, Sevilla, Extra! Comunicación, 2016.

Baquero, Miguel Ángel, Huellas en la Tierra. Anuario 2016-2017. Intervenciones en fosas comunes del franquismo en Andalucía, Sevilla, Extra! Comunicación, 2018.

Barrios, Manuel, El último rey. Queipo de Llano, Barcelona, Argos/Vergara, 1978.

Casanova, Julián, «Una dictadura de cuarenta años», en Julián Casanova, Francisco Espinosa, Conchita Mir y Francisco Moreno Gómez (eds.), Matar, morir, sobrevivir. La violencia en la dictadura de Franco, Barcelona, Crítica, 2002, pp. 3-50.

Casanova, Julián, Una violencia indómita: el siglo XX europeo, Barcelona, Crítica, 2020. $\mathrm{BaB}$.

Ghaves Palacios, Julián, La represión en la provincia de Cáceres durante la Guerra Civil (1936-1939), Cáceres, Universidad de Extremadura, 1995.

Chaves Palacios, Julián, La Guerra Civil en Extremadura. Operaciones militares (19361939), Mérida, Editora regional de Extremadura, 1997.

\footnotetext{
92 Nash, 2015; Sánchez Sánchez, 2009.

93 Sánchez Sánchez, 2009.

${ }^{9}$ Sánchez Sánchez, 2009, p. 219.
} 
Chaves Palacios, Julián, «Violencia de género y Primer Franquismo: culturas carcelarias y medidas asistenciales», en Lourenzo Fernández Prieto/Nomes e voces (eds.), Memoria de Guerra y cultura de paz en el siglo XX. De España a América, debates para una historiografía, Gijón, Ediciones Trea, 2012, pp. 273-293.

Chaves Palacios, Julián, Candela Chaves Rodríguez, Cayetano Ibarra Barroso, Javier Martín Bastos, y Laura Muñoz Encinar, Recuperación de la Memoria Histórica en Extremadura: Balance de una década (2003-2013). Investigación de la Guerra Civil y el Franquismo, Zafra, Rayego, 2013.

Chaves Rodríguez, Candela, Sentenciados. La represión franquista a través de la justicia militar y los consejos de guerra en la provincia de Badajoz, Badajoz, PREMHEX, 2015.

Crossland, Zoe, «Buried Lives», Archaeological Dialogues, 7.2, 2000, pp. 146-159.

Crossland, Zoe, «Of Clues and Signs: The Dead Body and Its Evidential Traces», American Anthropologist, 111.1, 2009, pp. 69-80.

Crossland, Zoe, «Evidential Regimes of Forensic Archaeology», Annual Review of Anthropology, 42.1, 2013, pp. 121-137.

Díaz-Ramoneda, Eulalia, Lourdes Herrasti, y Queralt Solé Barjau, «Archaeological Evidence of Gender Differences in Violent Repression: Exhumations of Women Killed during the Spanish Civil War and the Franco Dictatorship», Journal of Contemporary Archaeology, 7.2, 2020, pp. 209-226.

Espinosa Maestre, Francisco, «Julio de 1936. Golpe militar y plan de exterminio», en Julián Casanova, Francisco Espinosa, Conchita Mir y Francisco Moreno Gómez (eds.), Matar, morir, sobrevivir. La violencia en la dictadura de Franco, Barcelona, Crítica, 2002, pp. 51-119.

Espinosa Maestre, Francisco, La columna de la muerte. El avance del ejército franquista de Sevilla a Badajoz, Barcelona, Crítica, 2003.

Espinosa Maestre, Francisco, «El contexto de la Memoria. Represión», en Rafael Escudero Alday (coord.), Diccionario de memoria histórica. Conceptos contra el olvido, Madrid, Catarata, 2011, pp. 39-45.

Espinosa Maestre, Francisco, «Crímenes que no prescriben, 1936-1953», en Rafael Escudero Alday, y Carmen Pérez González (eds.), Desapariciones forzadas, represión política y crímenes del Franquismo, Madrid, Trota, 2013, pp. 31-54.

Espinosa Maestre, Francisco, Por la Sagrada Causa Nacional. Historia de un Tiempo Oscuro. Badajoz 1936-1939, Barcelona, Crítica, 2021.

Ferrándiz, Francisco, «Protocolo de entrevistas en exhumaciones de fosas comunes», http:// www.politicasdelamemoria.org/2010/10/protocolo-de-entrevistas-en-exhumaciones-de-fosas-comunes-francisco-ferrandiz-csic-3/, 2010 [consultado el 14/06/2021].

Ferrándiz, Francisco, El pasado bajo tierra. Exhumaciones contemporáneas de la Guerra Civil, Barcelona, Anthropos, 2014.

Funari, Pedro Paulo, y Andrés Zarankin (comps.), Arqueología de la represión y la resistencia en América Latina 1960-1980, Córdoba, Encuentro Grupo Editor, 2006.

Gebhardt, Miriam, Crimes Unspoken: The Rape of German Women at the End of the Second World War, Cambridge, Polity Press, 2017.

Gómez Bravo, Gutmaro, El exilio interior. Cárcel y represión en la España franquista (1939-1950), Madrid, Taurus, 2009.

González Duro, Enrique, Las rapadas: El franquismo contra la mujer, Madrid, Siǵlo XXI, 2017. 
González-Ruibal, Alfredo, «Absent bodies. The fate of the vanquished in the Spanish Civil War», en Paul Cornish, y Nicholas Sounders (eds.), Bodies in conflict. Corporeality, materiality and transformation, Oxon, Routledge, 2014, pp. 169-183.

González-Ruibal, Alfredo, The Archaeology of the Spanish Civil War, Abingdon, Routledge, 2020.

Harris, Edward C., Principios De Estratigrafía Arqueológica, Barcelona, Crítica, 1991.

Joly, Maud, «Las violencias sexuadas de la Guerra Civil española: Paradiǵma para una lectura cultural del conflicto», Historia social, 6, 2008, pp. 89-107.

Jones, Adam, «Gender and Genocide in Rwanda», Journal of Genocide Research, 4.1, 2002, pp. 65-94.

López Rodríguez, Antonio D., Cruz, Bandera y Caudillo. El campo de concentración de Castuera, Badajoz, CEDER-LaSerena, 2009.

Lorentzen, Lois Ann, y Jennifer E. Turpin (eds.), The Women and War Reader, New York, New York University Press, 1998.

Martín Bastos, Javier, Badajoz: Tierra quemada. Muertes a causa de la represión franquista 1936-1950, Badajoz, PREMHEX, 2015.

Molinero Ruiz, Carme (coord.), La Transición, treinta años después, Barcelona, Península, 2006.

Moreno, Manuel, «La dictadura franquista y la represión de las mujeres», en Mary Nash (ed.), Represión, resistencias, memoria: las mujeres bajo la dictadura franquista, Granada, Comares, 2013, pp.1-21.

Muñoz-Encinar, Laura, «De la exhumación de cuerpos al conocimiento histórico. Análisis de la represión irregular franquista a partir de la excavación de fosas comunes en Extremadura (1936-1948)», Tesis doctoral, Cáceres, Universidad de Extremadura, 2016.

Muñoz-Encinar, Laura, «De la exhumación de cuerpos al conocimiento histórico. Estudio de la represión franquista a partir del caso extremeño», Historia Contemporánea, 60.2, 2019a, pp. 477-508.

Muñoz-Encinar, Laura, «La violencia durante el siglo Xx. Búsqueda y exhumación de fosas de víctimas de ejecuciones extrajudiciales en Extremadura», en Julián Chaves Palacios (ed.), Mecanismos de control social y político en el Primer Franquismo, Barcelona, Anthropos, 2019b, pp. 189-226.

Muñoz-Encinar, Laura, «Unearthing gendered repression: an analysis of the violence suffered by women during the civil war and Franco's dictatorship in Southwestern Spain», World Archaeology 52 (5), 2019c, pp. 759-777. https://doi. org/10.1080/00438243.202 0.1740775

Muñoz-Encinar, Laura, Xurxo M. Ayán Vila, y Antonio. D. López-Rodríguez (eds.), De la ocultación de las fosas a las exhumaciones. La represión en el entorno del Campo de Concentración de Castuera, Santiago de Compostela, Incipit-CSIC/AMECADEC, 2013.

Muñoz-Encinar, Laura, y Julián Chaves Palacios, «Extremadura: Behind the material traces of Franco's repression», Culture \& History Digital Journal, 3.2, 2014, pp. 1-18.

Muñoz-Encinar, Laura, y Antonio J. Rodríguez-Hidalgo, «Excavación arqueológica de las fosas comunes de Escurial», en Ángel Olmedo (ed.), Guerra y Represión. Las Fosas de Escurial y Miajadas, Mérida, Asamblea de Extremadura, 2010, pp. 263-294.

Nash, Mary (ed.), Represión, resistencias, memoria: las mujeres bajo la dictadura franquista, Granada, Comares, 2013. 
Nash, Mary, «Vencidas, represaliadas y resistentes: las mujeres bajo el orden patriarcal franquista», en Julián Casanova (ed.), 40 años con Franco, Barcelona, Crítica, 2015, pp. 191-228.

Nash, Mary, y Susanna Tavera, El papel de las mujeres en las guerras de la Edad Antigua a la Contemporánea, Barcelona, Icasa, 2003.

Niarchos, Catherine N., «Women, War, and Rape: Challenges Facing the International Tribunal for the Former Yugoslavia», Human Rights Quarterly, 17.4, 1995, pp. 649-690.

Olmedo Alonso, Ángel, Llerena 1936. Fuentes orales para la recuperación de la memoria histórica, Badajoz, Diputación Provincial, 2010a.

Olmedo Alonso, Ángel, «Una experiencia de «Historia Viva» Miajadas y Escurial durante el verano del 2009. Voluntarios para la recuperación de la Memoria Histórica», en Ángel Olmedo (ed.), Guerra y Represión. Las Fosas de Escurial y Miajadas, Mérida, Asamblea de Extremadura, 2010b, pp. 155-261.

Preston, Paul, El holocausto español. Odio y exterminio en la Guerra Civil y después, Madrid, Debate, 2011.

Richards, Michael, Un tiempo de silencio. La Guerra Civil y la cultura de la represión en la España de Franco, 1936-1945, Barcelona, Crítica, 1999.

Ricoeur, Paul, Memory, History, Forgetting, London, The University of Chicago Press, 2004.

Rodrigo, Javier, Hasta la raíz: violencia durante la Guerra Civil y la dictadura franquista, Madrid, Alianza, 2008.

Rodrigo, Javier, y David Alegre, Comunidades Rotas. Una historia global de las guerras civiles, 1917-2017, Barcelona, Galaxia Gutenberg, 2019.

Sánchez Sánchez, Pura, Individuas de dudosa moral. La represión de las mujeres en Andalucía (1936-1959), Barcelona, Crítica, 2009.

Sanford, Victoria, Informe de la Fundación de Antropología Forense de Guatemala: cuatro casos paradigmáticos solicitados por la Comisión para el Esclarecimiento Histórico de Guatemala realizadas en las Comunidades de Panzós, Acuì, Chel y Belén, Guatemala City, FAFG, 2000.

Snyder, Cindy S., Wesley J. Gabbard, J. Dean May, y Nihada Zulcic, «On the Battleground of Women's Bodies: Mass Rape in Bosnia-Herzegovina», Affilia, 21.2, 2006, pp. 184-195.

Soh, C. Sara, The Comfort Women: Sexual Violence and Postcolonial Memory in Korea and Japan, Chicago, University of Chicago Press, 2010.

Solé, Queralt, «Executed Women, Assassinated Women: Gender Repression in the Spanish Civil War and the Violence of the Rebels», en Ofeflia Ferrán y Lisa Hilbink (eds.), Legacies of Violence in Contemporary Spain, London, Routledge, 2016, pp. 87-110.

United Nations, Revision of the UN Manual on the Effective Prevention and Investigation of Extra-legal, Arbitrary and Summary Executions (The Minnesota Protocol), Geneva, United Nations, 2016.

Vallejo-Nágera, Antonio, y Eduardo M. Martínez, «Psiquismo del fanatismo marxista. Investigaciones psicológicas en marxistas femeninos delincuentes», Revista Española de Medicina y Cirugía de Guerra, 9, 1939, pp. 398-413.

Vega Sombría, Santiago, La política del miedo. El papel de la represión en el franquismo, Barcelona, Crítica, 2011.

Vinyes, Ricard, Irredentas. Las presas políticas y sus hijos en las cárceles de Franco, Madrid, Ediciones Temas de Hoy, 2002. 